\title{
Fructo-oligosaccharide systemically diminished D-galactose-induced oxidative molecule damages in BALB/cJ mice
}

\author{
Chien-Hsun $\mathrm{Hsia}^{1}$, Cheng-Hsin Wang $^{2}$, Yi-Wen Kuo ${ }^{3}$, Ying-Jui Ho ${ }^{4}$ and Hsiao-Ling Chen ${ }^{3,5 *}$ \\ ${ }^{1}$ Division of Cardiology, Department of Internal Medicine, Changhua Christian Hospital, Changhua, Taiwan, ROC \\ ${ }^{2}$ Department of Food and Nutrition, Providence University, Taichung, ROC \\ ${ }^{3}$ School of Nutrition, Chung Shan Medical University, Taichung, ROC \\ ${ }^{4}$ School of Psychology, Chung Shan Medical University, No. 110, Sec. 1 Jianguo N. Road, Taichung City 402, Taiwan, ROC \\ ${ }^{5}$ Department of Nutrition, Chung Shan Medical University Hospital, No. 110, Sec. 1, Jianguo N. Road, Taichung City 402, \\ Taiwan, ROC
}

(Submitted 19 May 2011 - Final revision received 10 August 2011 - Accepted 16 August 2011 - First published online 20 September 2011)

\section{Abstract}

Subcutaneous (s.c.) D-galactose (DG) treatment has been shown to facilitate the development of biomarkers for Alzheimer's disease in $\mathrm{C} 57 \mathrm{BL} / 6 \mathrm{~J}$ mice. The aim of the present study was to determine whether this treatment in young BALB/cJ mice, another mouse strain, enhanced oxidative stress to similar extents shown in older mice, and to further determine the effects of fructo-oligosaccharide (FO), a prebiotic fibre and vitamin E (antioxidant control) on the DG-induced oxidative damage of lipids, proteins and mitochondrial DNA, and erythrocyte antioxidant enzyme activities. Mice (12 weeks of age, $n$ 40) were divided into four groups: vehicle (s.c. saline) + control (modified rodent chow); DG (s.c. $1 \cdot 2 \mathrm{~g} / \mathrm{kg}$ body weight) + control; DG + FO (5\%, w/w); DG + vitamin E ( $\alpha$-tocopherol, $0 \cdot 2 \%)$. Then, the animals were killed after $52 \mathrm{~d}$ of treatment. Another natural ageing (NA) group without any injection was killed at 47 weeks of age, which served as an aged control. The results indicated that the DG treatment enhanced malonaldehyde dimethyl acetal (MDA) levels in the plasma, liver and cerebral cortex, and protein carbonyl levels in the liver and hippocampus to similar levels shown in the NA group. FO, similar to $\alpha$-tocopherol, systemically normalised DG-induced elevations in the levels of MDA in the plasma, liver and cerebral cortex, protein carbonyls in the liver and hippocampus, hepatic mitochondrial 8-oxo-deoxyguanosine and erythrocyte superoxide dismutase activity. In conclusion, the s.c. DG treatment in younger BALB/cJ mice resembled the oxidative status in older mice. FO supplementation systemically prevented DG-induced oxidative stress, probably through its fermentation products and prebiotic effect.

Key words: D-Galactose: Fructo-oligosaccharides: Malonaldehyde dimethyl acetal: Protein carbonyls: 8-Oxo-deoxyguanosine

Free radical damage is considered to cause cell and tissue damage and ultimately results in ageing and cell death ${ }^{(1)}$. It has been shown that an overdose of D-galactose (DG) beyond the capacity of metabolism leads to the accumulation of galactitol, which in turn leads to osmotic stress and the generation of reactive oxygen species $^{(2)}$. In addition, DG is a reducing sugar that reacts with free amines of amino acids in proteins and peptides in vitro and in vivo to form advanced glycation end products ${ }^{(3)}$. The subcutaneous (s.c.) administration of DG in $\mathrm{C} 57 \mathrm{BL} / 6 \mathrm{~J}$ mice has been shown to enhance parameters of Alzheimer's disease ${ }^{(4)}$ and to cause neurological impairment ${ }^{(5,6)}$. However, systemic effects of this treatment on oxidative stress, especially in other mouse strains, have not been well established.
Fructo-oligosaccharides (FO), a prebiotic fibre with a wellrecognised stimulatory effect on bifidobacteria ${ }^{(7)}$, has been incorporated into drinks and desserts to improve the bowel function and faecal microflora profile in older nursing-home adults $^{(8,9)}$. Besides its wide application in bowel irregularity, FO may modulate oxidative stress through its role in the gut. We have shown in vitro antioxidative capacity from bifidobacteria-fermented $\mathrm{FO}^{(10)}$. A recent study has indicated that inulin, another oligofructose, ameliorated high-fat-induced oxidative damage and enhanced the gene expression of antioxidant enzymes not only in the colon, but also in the liver of Sprague-Dawley rats ${ }^{(11)}$. A clinical study has indicated that FO supplementation in older nursing-home adults causes a reduction in plasma lipid peroxide, which is correlated with

Abbreviations: 8-oxo-dG, 8-oxo-deoxyguanosine; DG, D-galactose; FO, fructo-oligosaccharide; GPx, glutathione peroxidase; MDA, malonaldehyde dimethyl acetal; NA, natural-ageing; s.c., subcutaneous; SOD, superoxide dismutase; TBA, thiobarbituric acid.

* Corresponding author: Dr H.-L. Chen, fax +886 423248175 , email hlchen908@gmail.com 
an increased faecal bifidobacteria population ${ }^{(9)}$. All these studies have suggested that FO may ameliorate oxidative stress systemically.

Authors have recently demonstrated that s.c. DG treatment in BALB/CJ mice induced alterations in hepatic antioxidant enzyme activities, and dietary FO reversed these alterations $^{(12)}$. However, the effects of DG on the formation of oxidative biomolecules in BALB/cJ mice have not been well studied, compared with older mice. Furthermore, the antioxidative effects of FO on these DG-induced alterations remain to be examined. There are two goals of the present study: (1) to compare the biomarkers of lipid, protein and DNA oxidation in tissues and plasma, and erythrocyte antioxidant enzymes between DG-treated young BALB/CJ mice and their natural ageing counterparts (aged control); (2) to determine the modulatory effects of FO and $\alpha$-tocopherol (antioxidant control) on these DG-induced alterations.

\section{Materials and methods}

\section{Animals and diets}

Male BALB/cJ mice (BioLASCO, Taipei, Taiwan) were housed (two animals per cage) in solid-bottomed plastic cages with wood shavings for bedding in a room maintained on a $12 \mathrm{~h}$ light-12 h dark cycle (08.00-20.00 hours) at $24 \pm 1^{\circ} \mathrm{C}$ and $50 \%$ humidity at the Experimental Animal Center of Chung Shan Medical University. After a week of adaptation, mice (12 weeks of age, $n$ 40) were randomly divided into four groups ( $n$ 10): vehicle + control (s.c. saline, basal diet); vehicle + DG (s.c. $1.2 \mathrm{~g} \mathrm{DG} / \mathrm{kg}$ body weight, basal diet); $\mathrm{DG}+\mathrm{FO}$ (50 g active ingredients/kg basal diet); DG + vitamin $\mathrm{E}$ ( $2 \mathrm{~g} \alpha$-tocopherol $/ \mathrm{kg}$ basal diet, as an antioxidant positive control). Then, the animals were killed after $52 \mathrm{~d}$ of treatment. The basal diet consisted of a ground rodent chow (Lab 5001; Purina Mills, St Louis, MO, USA) and sucrose that matched the digestible sugar present in the FO syrup (Institute of Microbial Resources, Taichung, Taiwan), as described previously $^{(12)}$. FO (Institute of Microbial Resources) contains fifty-one (39\%, w/w, dry basis) oligomers including fructosylnystose, nystose and kestose; the remaining are made of simple sugars, as described previously ${ }^{(8)}$. The mixed powder diet was then re-formed into a small dough with deionised water in order to balance the liquid content among the diets and to reduce spillage. The dose of FO and $\alpha$-tocopherol used in the present study was shown to exert prebiotic ${ }^{(7,9)}$ and antioxidative ${ }^{(13)}$ effects, respectively. Natural-ageing mice (NA group) that did not receive any injection were fed with a standard rodent diet (Lab 5001; Purina Mills) until the age of 39 weeks. They were then fed with the basal diet for $52 \mathrm{~d}$ and killed at the age of 47 weeks. All animals were allowed to have free access to water and food during the study. Animal care followed the guidelines of the National Research Council ${ }^{(14)}$ and was approved by the Institutional Animal Care and Use Committee at the Chung Shan Medical University. Mice were anaesthetised with $\mathrm{CO}_{2}$ on day 52 after a $20 \mathrm{~h}$ fasting. After blood samples were collected from the right atrium into heparinised tubes, mice were transcardially perfused with ice-cold normal saline for $15 \mathrm{~min}$. The cerebral cortex and hippocampus were dissected on an ice-cold plate, as described previously ${ }^{(15)}$, and the liver was dissected into three portions. The brain and liver samples were frozen immediately and stored at $-80^{\circ} \mathrm{C}$ for further analyses of oxidative stress indices. The blood samples were mixed with an equal volume of Histopaque ${ }^{\circledR}$ (Sigma, St Louis, MO, USA) and centrifuged at $3000 \mathrm{~g}$ for $10 \mathrm{~min}$ at $4^{\circ} \mathrm{C}$. The erythrocyte layers were washed with PBS, followed by the addition of a 4-fold volume of ice-cold distilled water, and then centrifuged at $10000 \boldsymbol{g}$ for $15 \mathrm{~min}$ at $4^{\circ} \mathrm{C}$. The supernatant, i.e. erythrocyte lysate, was collected and stored at $-80^{\circ} \mathrm{C}$ for further analyses of antioxidant enzyme activities.

\section{Malonaldehyde dimethyl acetal in the plasma, liver and cortex}

Malonaldehyde dimethyl acetal (MDA) levels were determined using 1,1,3,3-tetraethoxypropane (Sigma) as the standard using the method described by Hong et al. ${ }^{(16)}$. The hepatic tissues $(0 \cdot 2 \mathrm{~g})$ were homogenised in 9-fold volumes of $0 \cdot 1 \mathrm{M}$-potassium phosphate buffer containing $1 \cdot 15 \%(\mathrm{w} / \mathrm{v})$ potassium chloride $(\mathrm{pH} \mathrm{7.0)}$ and centrifuged at $12000 \boldsymbol{g}$ for $10 \mathrm{~min}$ to obtain the supernatant. After incubation with 5-fold volumes of TCA $(7 \cdot 2 \%, \mathrm{w} / \mathrm{v}$, containing $1 \%, \mathrm{w} / \mathrm{v}$, potassium iodide) in ice for $10 \mathrm{~min}$, the samples were centrifuged at $12000 \mathrm{~g}$ for $10 \mathrm{~min}$. An aliquot $(0.5 \mathrm{ml})$ of this supernatant was mixed with $1 \mathrm{ml}$ of $0.6 \%(\mathrm{w} / \mathrm{v})$ thiobarbituric acid (TBA) at $95^{\circ} \mathrm{C}$ for $1 \mathrm{~h}$, and the MDA-TBA adduct was extracted with $n$-butanol. The MDA-TBA adduct was eluted with a mixture of phosphate buffer $(50 \mathrm{~mm})$ and methanol $(65: 35, \mathrm{v} / \mathrm{v})$ at $0.8 \mathrm{ml} / \mathrm{min}$ in a HPLC system (Jasco, Tokyo, Japan) equipped with a C18 reverse-phase column (LiChroCART 250-4; Merck, Darmstadt, Germany) capped with a guard column (LiChrospher 100 RP-18e; Merck). The quantification of the MDA-TBA adduct was determined at $532 \mathrm{~nm}$ and quantified with a standard curve. All samples were determined in triplicate assays.

\section{Protein carbonyls in the liver and hippocampus}

Carbonyl proteins, a protein oxidation index, were determined according to the method described by Reznick \& Packer $^{(17)}$. The liver tissue $(0 \cdot 2 \mathrm{~g})$ and hippocampus were homogenised (20 mM-Tris buffer, $0 \cdot 137 \mathrm{M}-\mathrm{NaCl}, 10 \%$ glycerol, $1 \%$ Triton X-100, 2 mm-EDTA, $1 \%$ protease, $\mathrm{pH} 8.0$ ) and centrifuged at $10000 \mathrm{~g}$ for $15 \mathrm{~min}$ at $4^{\circ} \mathrm{C}$. The supernatant was treated with $1 \%(\mathrm{w} / \mathrm{w})$ streptomycin sulphate for $15 \mathrm{~min}$ to remove nucleic acids. The carbonyl groups derivatised to 2,4-dinitrophenylhydrazone by the reaction with 2,4-dinitrophenylhydrazine were determined at $380 \mathrm{~nm}$. Protein contents were determined with the Bradford method using a protein reagent (Bio-Rad Laboratories, Herculus, CA, USA), with bovine serum albumin as the standard. All samples were determined in triplicate assays. 


\section{Hepatic mitochondrial 8-oxo-deoxyguanosine}

Hepatic mitochondria were isolated according to the method described previously ${ }^{(18)}$. Briefly, liver tissue $(\sim 0 \cdot 1 \mathrm{~g})$ was homogenised in a 4 -fold volume of isolation buffer $(0 \cdot 25 \mathrm{M}-$ sucrose, $10 \mathrm{~mm}$-Tris and $0.5 \mathrm{~mm}$-EDTA, $\mathrm{pH}$ 7.4). After the nuclei and cell debris were sedimented by centrifugation at $2000 \mathrm{~g}$ for $3 \mathrm{~min}$ at $4^{\circ} \mathrm{C}$, the supernatant was subjected to a further centrifugation at $12500 \mathrm{~g}$ for $8 \mathrm{~min}$. The crude mitochondrial DNA was isolated with $\mathrm{REzol}^{\mathrm{TM}}$ C\&T reagent (Protech Systems Co., Taipei, Taiwan) following the manufacturer's protocol. The isolated DNA $(200 \mu \mathrm{g})$ was treated with $20 \mathrm{U}$ nuclease P1 and $1.5 \mathrm{IU}$ alkaline phosphatase ${ }^{(19)}$, and was analysed using a competitive enzyme immunoassay (Cayman Chemical Co, Ann Arbor, MI, USA) according to the protocol provided by the manufacturer. All samples were determined in duplicate assays.

\section{Erythrocyte antioxidant enzyme activities}

Superoxide dismutase (SOD), glutathione peroxidase (GPx) and catalase activities were determined in erythrocyte lysates. SOD activity was measured based on the competition for superoxide radicals between SOD and a tetrazolium salt ${ }^{(20)}$. GPx activity was measured indirectly by a coupled reaction with glutathione reductase that converted the oxidised glutathione to its reduced form with a concomitant oxidation of $\mathrm{NADPH}$ to $\mathrm{NADP}^{+(21)}$. Catalase activity was measured based on the transformation from methanol to formaldehyde that reacted with 4-amino-3-hydrazino-5-mercapto-1,2,4-tria$z \mathrm{zol}^{(22)}$. Hb contents of the erythrocyte lysate were analysed following the manufacturer's protocol (Sigma). Enzyme activity was expressed as IU/mg $\mathrm{Hb}$. All samples were determined in triplicate assays.

\section{Statistical analysis}

Data are expressed as means with their standard errors, and analysed using SPSS version 12 (SPSS, Inc., Chicago, IL, USA). Differences between groups were analysed by oneway ANOVA, followed by the least significant difference test. Differences were considered significant at $P<0 \cdot 05$.

\section{Results}

\section{Weight gain, feed intake and feed efficiency}

Data of the growth and feed intake in young mice receiving $52 \mathrm{~d}$ of s.c. vehicle or DG injection are shown in Table 1. Body-weight gain was the lowest in DG-treated mice without any supplementation (DG + control group), and the greatest in the DG + FO group. Daily feed intake was the lowest in the DG + control group and similar among the other groups. Feed efficiency (body-weight gain/feed intake) was the greatest in the DG + FO group and was similar among the other groups. Age and diet for the NA group were different from the other treated groups. Therefore, the related data are not shown in Table 1 . The body weight of NA mice was 34.6
Table 1. Body-weight gain, feed intake and feed efficiency in various groups of BALB/cJ mice

(Mean values with their standard errors, $n$ 10)

\begin{tabular}{|c|c|c|c|c|c|c|}
\hline \multirow[b]{2}{*}{ Group } & \multicolumn{2}{|c|}{$\begin{array}{l}\text { Body-weight } \\
\text { gain }(\mathrm{g})\end{array}$} & \multicolumn{2}{|c|}{$\begin{array}{l}\text { Feed intake } \\
\qquad(\mathrm{g} / \mathrm{d})\end{array}$} & \multicolumn{2}{|c|}{$\begin{array}{c}\text { Feed } \\
\text { efficiency }(\%)^{\star}\end{array}$} \\
\hline & Mean & SE & Mean & SE & Mean & SE \\
\hline Vehicle + control & $3 \cdot 8^{\mathrm{b}, \mathrm{c}}$ & 0.2 & $5 \cdot 4^{\mathrm{b}}$ & 0.3 & $1 \cdot 6^{a, b}$ & 0.1 \\
\hline $\mathrm{DG}+$ control & $2 \cdot 8^{\mathrm{a}}$ & 0.2 & $4 \cdot 6^{a}$ & 0.2 & $1 \cdot 4^{\mathrm{a}}$ & 0.1 \\
\hline $\mathrm{DG}+\mathrm{FO}$ & $4 \cdot 2^{c}$ & 0.3 & $5 \cdot 6^{b}$ & 0.1 & $1 \cdot 7^{\mathrm{b}}$ & 0.1 \\
\hline $\mathrm{DG}+$ vitamin $\mathrm{E}$ & $3 \cdot 2^{a, b}$ & 0.2 & $5 \cdot 2^{b}$ & 0.2 & $1.4^{\mathrm{a}}$ & 0.1 \\
\hline
\end{tabular}

DG, D-galactose; FO, fructo-oligosaccharide.

a,b,c Mean values with unlike superscript letters within a column were significantly different $(P<0.05$; ANOVA followed by the least significant difference test).

${ }^{*}$ Feed efficiency $(\%)=$ body-weight gain $(\mathrm{g} / \mathrm{d}) /$ feed intake $(\mathrm{g} / \mathrm{d}) \times 100 \%$.

(SE $0 \cdot 3) \mathrm{g}$ at the end of the experiment; their daily food intake was $4.0(\operatorname{se~} 0 \cdot 2) \mathrm{g}$ during the last week of the experiment.

\section{Plasma, liver and cerebral cortex malonaldehyde dimethyl acetal}

The DG treatment alone significantly elevated the formation of MDA in the plasma, liver and cerebral cortex when compared with the vehicle-treated counterpart (Table 2). The formation of MDA in the plasma, liver and cerebral cortex was similar to what was observed in the NA group. Both FO and $\alpha$-tocopherol attenuated the effect of DG on the plasma MDA level, and completely diminished its effect in the liver and cerebral cortex. $\alpha$-Tocopherol further suppressed the cortex MDA level to only $83 \cdot 1 \%$ of that in the vehicle + control group.

\section{Protein carbonyls in the liver and hippocampus}

Both hepatic and hippocampus protein carbonyl levels were similar between the NA and DG + control groups (Table 3). Both FO and $\alpha$-tocopherol diminished the effect of the DG treatment on hepatic protein carbonyl levels, and further reduced the levels to about 80.0 and about $56.0 \%$ of that shown in the vehicle + control group, respectively. In the hippocampus, both FO and $\alpha$-tocopherol diminished the effect of the DG treatment on protein carbonyl levels, while $\alpha$-tocopherol further suppressed the levels lower than that in the vehicle + control group.

Table 2. Malonaldehyde dimethyl acetal levels in the plasma, liver and cerebral cortex in various groups of BALB/cJ mice

(Mean values with their standard errors, $n 10$ )

\begin{tabular}{|c|c|c|c|c|c|c|}
\hline \multirow[b]{2}{*}{ Group } & \multicolumn{2}{|c|}{$\begin{array}{c}\text { Plasma } \\
(\mu \mathrm{M})\end{array}$} & \multicolumn{2}{|c|}{$\begin{array}{c}\text { Liver } \\
(\mathrm{nmol} / \mathrm{g})\end{array}$} & \multicolumn{2}{|c|}{$\begin{array}{l}\text { Cortex } \\
(\mathrm{nmol} / \mathrm{g})\end{array}$} \\
\hline & Mean & SE & Mean & SE & Mean & SE \\
\hline Natural ageing & $20 \cdot 5^{c}$ & $2 \cdot 7$ & $92.5^{\mathrm{b}}$ & $4 \cdot 0$ & $100 \cdot 7^{c}$ & $5 \cdot 3$ \\
\hline Vehicle + control & $13 \cdot 4^{\mathrm{a}}$ & $2 \cdot 1$ & $75 \cdot 4^{a}$ & 3.3 & $92 \cdot 6^{\mathrm{b}}$ & $6 \cdot 1$ \\
\hline DG + control & $21 \cdot 0^{\mathrm{C}}$ & $2 \cdot 6$ & $94.9^{b}$ & $5 \cdot 3$ & $100 \cdot 2^{\mathrm{c}}$ & $5 \cdot 1$ \\
\hline $\mathrm{DG}+\mathrm{FO}$ & $15 \cdot 5^{a, b}$ & 1.4 & $72 \cdot 4^{a}$ & 5.5 & $94.7^{\mathrm{b}}$ & $7 \cdot 4$ \\
\hline $\mathrm{DG}+$ vitamin $\mathrm{E}$ & $16 \cdot 7^{\mathrm{b}}$ & $2 \cdot 3$ & $62 \cdot 8^{\mathrm{a}}$ & 5.5 & $68 \cdot 6^{\mathrm{a}}$ & $5 \cdot 2$ \\
\hline
\end{tabular}

DG, D-galactose; FO, fructo-oligosaccharide.

${ }_{a, b, c}$ Mean values with unlike superscript letters within a column were significantly different $(P<0.05$; ANOVA followed by the least significant difference test). 
Table 3. Protein carbonyl levels in the liver and hippocampus in various groups of BALB/cJ mice

(Mean values with their standard errors, $n 10$ )

\begin{tabular}{|c|c|c|c|c|}
\hline \multirow[b]{3}{*}{ Group } & \multicolumn{4}{|c|}{ Protein carbonyls (nmol/mg protein) } \\
\hline & \multicolumn{2}{|c|}{ Liver } & \multicolumn{2}{|c|}{ Hippocampus } \\
\hline & Mean & SE & Mean & $\mathrm{SE}$ \\
\hline Natural ageing & $3 \cdot 4^{d}$ & 0.2 & $8.0^{\mathrm{b}}$ & 0.9 \\
\hline Vehicle + control & $2 \cdot 5^{\mathrm{b}, \mathrm{c}}$ & 0.3 & $6 \cdot 2^{\mathrm{a}}$ & 0.4 \\
\hline $\mathrm{DG}+$ control & $3 \cdot 0^{c, d}$ & 0.3 & $8.9^{b}$ & $1 \cdot 2$ \\
\hline $\mathrm{DG}+\mathrm{FO}$ & $2 \cdot 0^{\mathrm{a}, \mathrm{b}}$ & 0.3 & $6 \cdot 8^{\mathrm{a}}$ & 0.8 \\
\hline $\mathrm{DG}+\operatorname{vitamin} \mathrm{E}$ & $1.4^{\mathrm{a}}$ & 0.2 & $7 \cdot 2^{\mathrm{a}}$ & 0.2 \\
\hline
\end{tabular}

DG, D-galactose; FO, fructo-oligosaccharide.

$a, b, c, d$ Mean values with unlike superscript letters within a column were significantly different $(P<0.05$; ANOVA followed by the least significant difference test).

\section{Hepatic mitochondrial 8-oxo-deoxyguanosine}

The oxidative modification of hepatic mitochondrial DNA is shown in Fig. 1. The mitochondrial 8-oxo-deoxyguanosine (8-oxo-dG) levels in the $\mathrm{NA}$ and $\mathrm{DG}+$ control groups were significantly elevated by about 80 and $40 \%$, respectively, compared with that in the vehicle + control group. FO and vitamin $\mathrm{E}$ did not just diminish the effect of DG, but further suppressed the formation of 8-oxo-dG to levels lower than that shown in the vehicle + control group.

\section{Erythrocyte antioxidant enzyme activities}

SOD activities in both NA and DG + control groups were significantly greater than that in the vehicle + control group (Table 4). Dietary FO and vitamin E normalised the alteration induced by the DG treatment. GPx activity was drastically elevated by the DG treatment to more than 3-fold of that in

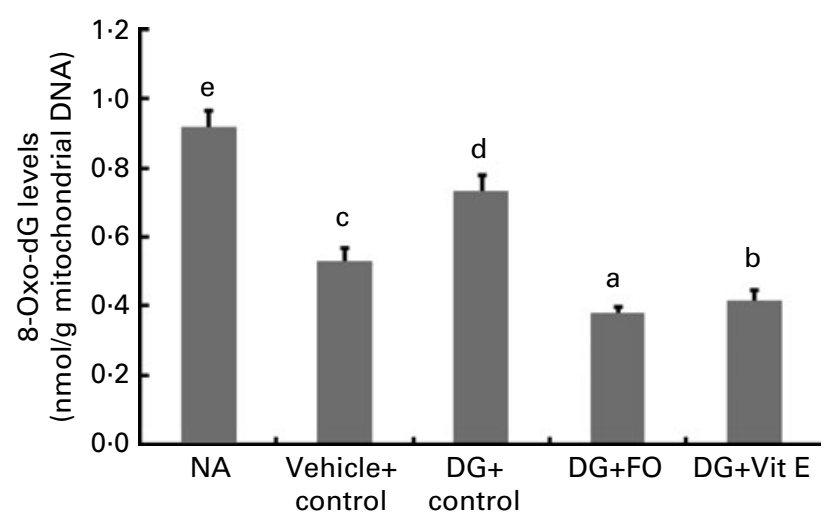

Fig. 1. Hepatic mitochondrial 8-oxo-deoxyguanosine (8-oxo-dG) levels in natural ageing mice (47 weeks old; NA group) or young male BALB/cJ mice (about 19 weeks old) subcutaneously treated with vehicle (saline) or D-galactose (DG). The vehicle-treated group was fed the control diet (vehicle + control group) while DG-treated mice were fed with the control diet (DG + control group), the fructo-oligosaccharide (FO) diet $(50 \mathrm{~g}$ active ingredients $/ \mathrm{kg}$ diet; $\mathrm{DG}+\mathrm{FO}$ group) or the vitamin (Vit) $\mathrm{E}$ diet $(2 \mathrm{~g} \alpha$-tocopherol $/ \mathrm{kg}$ diet, as an antioxidant positive control; DG + Vit E group). Values are means, with their standard errors represented by vertical bars $(n 10) .{ }^{\mathrm{a}, \mathrm{b}, \mathrm{c}, \mathrm{d}, \mathrm{e}}$ Mean values with unlike letters were significantly different $(P<0.05)$.
Table 4. Erythrocyte antioxidant enzyme activities in various groups of BALB/cJ mice

(Mean values with their standard errors, $n$ 10)

\begin{tabular}{|c|c|c|c|c|c|c|}
\hline \multirow[b]{2}{*}{ Group } & \multicolumn{2}{|c|}{$\begin{array}{c}\text { SOD } \\
(\mathrm{kIU} / \mathrm{g} \mathrm{Hb})\end{array}$} & \multicolumn{2}{|c|}{$\begin{array}{c}\text { GPx } \\
(\mathrm{IU} / \mathrm{g} \mathrm{Hb})\end{array}$} & \multicolumn{2}{|c|}{$\begin{array}{l}\text { Catalase } \\
(\mathrm{IU} / \mathrm{g} \mathrm{Hb})\end{array}$} \\
\hline & Mean & SE & Mean & SE & Mean & SE \\
\hline Natural ageing & $7 \cdot 9^{d}$ & 0.3 & $4 \cdot 6^{\mathrm{a}, \mathrm{b}}$ & 0.4 & $167 \cdot 2^{a}$ & $4 \cdot 8$ \\
\hline Vehicle + control & $4 \cdot 8^{a, b}$ & 0.2 & $2 \cdot 9^{a}$ & 0.2 & $255 \cdot 5^{b}$ & $16 \cdot 7$ \\
\hline $\mathrm{DG}+$ control & $6 \cdot 1^{\mathrm{c}}$ & 0.3 & $10 \cdot 7^{c}$ & $1 \cdot 3$ & $250 \cdot 1^{b}$ & $10 \cdot 2$ \\
\hline $\mathrm{DG}+\mathrm{FO}$ & $4 \cdot 4^{a}$ & 0.2 & $9 \cdot 5^{\mathrm{C}}$ & $1 \cdot 1$ & $301 \cdot 8^{c}$ & $14 \cdot 7$ \\
\hline $\mathrm{DG}+$ vitamin $\mathrm{E}$ & $5 \cdot 3^{b}$ & 0.2 & $5 \cdot 8^{\mathrm{b}}$ & $1 \cdot 3$ & $372 \cdot 5^{d}$ & $19 \cdot 5$ \\
\hline
\end{tabular}

SOD, superoxide dismutase; GPx, glutathione peroxidase; DG, D-galactose; FO, fructo-oligosaccharide.

a,b,c,d Mean values with unlike superscript letters within a column were significantly different $(P<0.05$; ANOVA followed by the least significant difference test).

the vehicle + control group, but only slightly greater in the NA group. $\alpha$-Tocopherol, but not FO, significantly reduced the altered GPx activity induced by the DG treatment. Catalase activity was the lowest in the NA group, and the DG treatment did not modulate this enzyme activity when compared with the vehicle treatment. Dietary FO and $\alpha$-tocopherol significantly increased the catalase activity by 20.7 and about $50.0 \%$, respectively, compared with that in the DG + control group.

\section{Discussion}

DG treatment in $\mathrm{C} 57 \mathrm{BL} / 6 \mathrm{~J}$ mice has been shown to enhance oxidative stress and neurological dysfunction ${ }^{(4-6)}$. The physiological responses to DG-induced oxidative stress have not been well established in various strains of mice. Therefore, in the present study, we thoroughly determined the status of lipid, protein and DNA oxidation, and erythrocyte antioxidant enzymes in older mice (NA group, 47 weeks old), younger mice (vehicle + control group, about 19 weeks old) and DG-treated young BALB/CJ mice. The results indicated that all of the oxidative products measured in the present study increased with age. DG treatment increased the levels of MDA in the plasma, liver and brain, and the levels of hippocampus protein carbonyls and hepatic mitochondrial 8-oxo dG to the same extent as observed in older mice. Therefore, the present study suggests that DG treatment accelerates ageing by increasing systemic oxidative stress, and DG-treated BALB/CJ mice could be another experimental model of oxidative-induced ageing.

The older population may be confronted with limited intake of fibre-rich food and associated antioxidants ${ }^{(23,24)}$. Insufficient intake of dietary fibre jeopardises bowel function while decreased antioxidant intake hampers the defence machinery against free radicals. Fructo-oligosaccharide is considered to be a functional fibre that normalises bowel function and stimulates the growth of bifidobacteria in the constipated older population ${ }^{(8,9)}$. We have preliminarily found that $\mathrm{FO}$ $(5 \%, \mathrm{w} / \mathrm{w}$ diet $)$, similar to the antioxidant $\alpha$-tocopherol $(0 \cdot 2 \%, \mathrm{w} / \mathrm{w}$ diet $)$, normalised DG-induced alterations of hepatic SOD and GPx activities in BALB/CJ mice ${ }^{(12)}$. In agreement with that, the present results indicate that $\mathrm{FO}$, generally similar to $\alpha$-tocopherol, successfully diminishes the 
DG-induced oxidative modifications of lipids in the plasma, liver and cortex, proteins in the liver and hippocampus, and hepatic mitochondrial DNA, and normalises the DG-induced alteration of erythrocyte SOD activities. Since FO is a wellrecognised prebiotic fibre, the present study suggests that FO modulates systemic oxidative stress via its role in the intestine.

The central nervous system is vulnerable to oxidative insult on account of the high rate of oxygen utilisation, the relatively poor concentrations of classical antioxidants, antioxidant enzymes and high phospholipid content ${ }^{(25)}$. Increased oxidative damage is associated with age-related neurodegenerative diseases, such as Alzheimer's disease ${ }^{(25)}$. In the present study, the DG treatment enhanced the levels of cerebral cortex MDA and hippocampus protein carbonyls, suggesting that this treatment caused oxidative damages in the brain and could result in neurological alteration. Furthermore, this is the first study indicating that dietary supplementation of FO could protect the brain from oxidative damage. In the present study, $\alpha$-tocopherol supplementation exerted strong protective effects on oxidative modifications of lipids and proteins in the brain, suggesting its role in preventing oxidative stress-related neurological alteration. These results supported the role of vitamin $\mathrm{E}$ in protecting human cognitive function $^{(26)}$ and preventing Alzheimer's disease ${ }^{(27)}$. Although FO suppressed oxidative damage in the brain, its effect on neurological dysfunction and the mechanism underlying these effects remains to be investigated.

The liver is a major organ involved in carbohydrate, lipid and protein metabolism that produces abundant free radicals. It has been reported that age and DG treatment decrease major antioxidant enzymes in the liver ${ }^{(12)}$. In the present study, we specifically determined the effects of DG treatment on hepatic mitochondrial DNA damage, in addition to MDA and protein carbonyl levels, and further examined whether FO and $\alpha$-tocopherol could suppress the DG-induced alterations. We found that hepatic levels of mitochondrial 8-oxo-dG and MDA were significantly elevated in both NA and DG + control groups, and the DG treatment slightly enhanced the hepatic protein carbonyl levels, which is in agreement with lowered hepatic SOD activities as shown in our previous study ${ }^{(12)}$. FO and $\alpha$-tocopherol reversed the DG-induced elevations in the mitochondrial 8-oxo-dG, MDA and protein carbonyl levels in the present study, which are in agreement with their effects on normalising the DG-induced reduction in hepatic SOD levels ${ }^{(12)}$. Therefore, the present study confirmed a FO- and $\alpha$-tocopherolreduced hepatic oxidative stress induced by DG treatment in BALB/cJ mice via elevating the hepatic antioxidant enzyme activities.

The present study indicates that plasma lipid peroxide is enhanced by age and DG treatment, similar to what was observed previously in $\mathrm{C} 57 \mathrm{BL} / 6 \mathrm{~J}$ mice $^{(4)}$. FO supplementation reduced the MDA level, in agreement with its effect in nursinghome residents ${ }^{(9)}$. Erythrocyte antioxidant defence systems are confronted with oxidative challenges from plasma free radicals, macrophages, auto-oxidation of $\mathrm{Hb}$, and potential peroxidation of membrane lipids ${ }^{(28)}$. However, the effects of age and DG treatment on blood erythrocyte antioxidant enzyme activities have not been well studied. A previous study has examined age-related changes in erythrocyte antioxidant enzyme activities in Sprague-Dawley male rats and found that erythrocyte SOD activity increased, while GPX and catalase activities decreased, with age ${ }^{(29)}$. The present results indicate similar age-dependent changes in erythrocyte SOD and catalase activities, but GPx did not decrease with age. These differences between studies may result from differences in animals, diet and age. In the present study, the DG treatment increased erythrocyte SOD activity, which was diminished by FO and $\alpha$-tocopherol to the level observed in the vehicle + control group. The DG-induced augmentation of erythrocyte GPx was suppressed only in mice supplemented with $\alpha$-tocopherol, but not with FO, which could be due to the strong antioxidant effect of $\alpha$-tocopherol on the peroxidation of erythrocyte membrane lipids. On the other hand, the DG treatment did not reduce erythrocyte catalase activity when compared with the control, but FO and $\alpha$-tocopherol further elevated the activity. Antioxidants such as $\beta$-carotene and canthaxanthin have been shown to increase erythrocyte catalase activities ${ }^{(13)}$, which suggest that FO enhanced the erythrocyte antioxidant defence system in a manner similar to antioxidants.

The present study further indicates the preventive and systemic effects of FO on DG-induced oxidative modifications of lipids, proteins and DNA. Although mechanisms for the in vivo antioxidative ability of FO remain unclear, it is likely to be related to its prebiotic effect and its fermentation products. Several studies have indicated in vitro antioxidative capacities of lactic acid bacteria ${ }^{(30,31)}$. We have also reported that the effect of FO on reducing plasma lipid peroxide was associated with increases in the faecal bifidobacteria population ${ }^{(9)}$. In addition, previous studies have indicated that fermentation of FO by several species of bifidobacteria eliminated free radicals ${ }^{(10)}$. Therefore, we suggest that FO may diminish DG-induced oxidative stress by contributing antioxidants produced from its fermentation in the colon, and by stimulating the proliferation of colonic bacteria that exert antioxidative capacity.

In conclusion, the results of the present study indicate that s.c. administration of DG in BALB/CJ mice generally enhances parameters of oxidative stress in the plasma, liver and brain, to levels similar to that observed in older mice. FO, similar to the antioxidant $\alpha$-tocopherol, was found to effectively reduce the systemic oxidative stress induced by the DG treatment, which is probably due to its fermentation in the colon and the proliferation of colonic bacteria that exert antioxidative capacity.

\section{Acknowledgements}

The present study was supported by grant 98-CCH-CSMU-01 co-funded by the Changhua Christian Hospital and Chung Shan Medical University. C.-H. H. conducted the study. H.-L. C. designed and carried out the study, and wrote the manuscript. C.-H. W. collated and analysed the data, and co-wrote the manuscript. Y.-W. K. carried out the study. Y.-J. H. assisted in the mouse brain dissection and blood 
collection. The sponsor of FO by the Institute of Microbial Resources was greatly appreciated. All authors read and approved the findings of the study. There are no conflicts of interest.

\section{References}

1. Harman D (1956) Aging: a theory based on free radical and radiation chemistry. J Gerontol 11, 298-300.

2. Wang Z (1999) Physiologic and biochemical changes of mimetic aging induced by D-galactose in rats. Lab Anim Sci Admin 16, 23-25.

3. Bucala R \& Cerami A (1992) Advanced glycosylation: chemistry, biology, and implications for diabetes and aging. $A d v$ Pharmacol 23, 1-34.

4. Hsieh HM, Wu WM \& Hu ML (2009) Soy isoflavones attenuate oxidative stress and improve parameters related to aging and Alzheimer's disease in $\mathrm{C} 57 \mathrm{BL} / 6 \mathrm{~J}$ mice treated with D-galactose. Food Chem Toxicol 47, 625-632.

5. Cui X, Zuo P, Zhang Q, et al. (2006) Chronic systemic $\mathrm{D}$-galactose exposure induces memory loss, neurodegeneration, and oxidative damage in mice: protective effects of R-alpha-lipoic acid. J Neurosci Res 83, 1584-1590.

6. Zhang Q, Li X, Cui X, et al. (2005) D-Galactose injured neurogenesis in the hippocampus of adult mice. Neurol Res 27, 552-556.

7. Gibson GR (1999) Dietary modulation of the human gut microflora using the prebiotics oligofructose and inulin. J Nutr 129, 1438S-1441S.

8. Chen H-L, Lu Y-H, Lin J-J, et al. (2000) Effects of fructooligosaccharide on bowel function and indicators of nutritional status in constipated elderly men. Nutr Res 20, 1725-1733.

9. Yen C-H, Kuo Y-W, Tseng Y-H, et al. (2011) Beneficial effects of fructo-oligosaccharides supplementation on fecal bifidobacteria and index of peroxidation status in constipated nursing-home residents - a placebo-controlled, diet-controlled trial. Nutrition 27, 323-328.

10. Wang C-H, Lai P, Chen M-E, et al. (2008) Antioxidative capacity produced by Bifidobacterium- and Lactobacillus acidophilus-mediated fermentations of konjac glucomannan and glucomanan oligosaccharides. J Sci Food Agric 88, $1294-1300$.

11. Wu W-T \& Chen H-L (2011) Konjac glucomannan and inulin systematically modulated the antioxidant defense in rats fed a high-fat fiber-free diet. J Agric Food Chem (epublication ahead of print version 29 July 2011).

12. Chen H-L, Wang C-H, Kuo Y-W, et al. (2011) Anti-oxidative and hepato-protective effects of fructooligosaccharide in D-galactose treated Balb/cJ mice. Br J Nutr 105, 805-809.

13. Shih CK, Chang JH, Yang SH, et al. (2008) Beta-Carotene and canthaxanthin alter the pro-oxidation and antioxidation balance in rats fed a high-cholesterol and high-fat diet. Br J Nutr 99, 59-66.

14. National Institute of Health (1985) Guide for the Care and Use of Laboratory Animals (Publication 85-23, Rev.). Bethesda, MD: National Research Council, National Institute of Health.
15. Wang WF, Wu SL, Liou YM, et al. (2009) MPTP lesion causes neuroinflammation and deficits in object recognition in Wistar rats. Behav Neurosci 123, 1261-1270.

16. Hong Y, Yen S, Chang C, et al. (2000) Total plasma malondialdehyde levels in 16 Taiwanese college students determined by various thiobarbituric acid tests and an improved high-performance liquid chromatography-based method. Clin Biochem 33, 619-625.

17. Reznick AZ \& Packer L (1994) Oxidative damage to proteins: spectrophotometric method for carbonyl assay. Methods Enzymol 233, 357-363.

18. Lai JC \& Clark JB (1979) Preparation of synaptic and nonsynaptic mitochondria from mammalian brain. Methods Enzymol 55, 51-60.

19. Shigenaga MK, Park JW, Cundy KC, et al. (1990) In vivo oxidative DNA damage: measurement of 8-hydroxy-2'-deoxyguanosine in DNA and urine by high-performance liquid chromatography with electrochemical detection. Methods Enzymol 186, 521-530.

20. Flohé L, Becker R, Brigelius R, et al. (1992) Convenient assays for superoxide dismutase. In CRC Handbook of Free Radicals and Antioxidants in Biomedicine, pp. 287-293 [J Miquel, AT Quintanilha and $\mathrm{H}$ Weber, editors]. Boca Raton, FL: CRC Press.

21. Flohé L \& Gunzler WA (1984) Assays of glutathione peroxidase. Methods Enzymol 105, 114-121.

22. Johansson LH \& Håkan Borg LA (1988) A spectrophotometric method for determination of catalase activity in small tissue samples. Anal Biochem 174, 331-336.

23. Ervin RB \& Dye BA (2009) The effect of functional dentition on healthy eating index scores and nutrient intakes in a nationally representative sample of older adults. $J$ Public Health Dent 69, 207-216.

24. Hildebrandt GH, Dominguez BL, Schork MA, et al. (1997) Functional units, chewing, swallowing, and food avoidance among the elderly. J Prosthet Dent 77, 588-595.

25. Sayre LM, Perry G \& Smith MA (2008) Oxidative stress and neurotoxicity. Chem Res Toxicol 21, 172-188.

26. Morris MC, Evans DA, Bienias JL, et al. (2002) Vitamin E and cognitive decline in older persons. Arch Neurol 59, 1125-1132.

27. Morris MC, Evans DA, Tangney CC, et al. (2005) Relation of the tocopherol forms to incident Alzheimer disease and to cognitive change. Am J Clin Nutr 81, 508-514.

28. Halliwell B \& Gutteridge JMC (2003) Free Radicals in Biology and Medicine. New York, NY: Oxford University Press.

29. Rho KA \& Kim MK (2006) Effects of different grape formulations on antioxidative capacity, lipid peroxidation and oxidative DNA damage in aged rats. J Nutr Sci Vitaminol 52, 33- 46.

30. Lin M-Y \& Yen C-L (1999) Antioxidative ability of lactic acid bacteria. J Agric Food Chem 47, 1460-1466.

31. Zanoni S, Pompei A, Cordisco L, et al. (2008) Growth kinetics on oligo- and polysaccharides and promising features of three antioxidative potential probiotic strains. J Appl Microbiol 105, 1266-1276. 